\title{
Functional role of autophagy in gastric cancer
}

\author{
Hao-ran Qian ${ }^{1, *}$ and Yi Yang ${ }^{2, *}$ \\ ${ }^{1}$ Department of General Surgery, Institute of Micro-Invasive Surgery of Zhejiang University, Sir Run Run Shaw Hospital, \\ Medical College of Zhejiang University, Hangzhou, Zhejiang, PR China \\ 2 Department of Pharmacology, Hangzhou Key Laboratory of Medical Neurobiology, School of Medicine, Hangzhou Normal \\ University, Hangzhou, Zhejiang, PR China \\ * These authors have contributed equally to this work \\ Correspondence to: Hao-ran Qian, email: qianhr@srrsh.com \\ Yi Yang, email: yyang@hznu.edu.cn \\ Keywords: autophagy, autophagy-related gene, gastric cancer, tumorigenesis, progression \\ Received: September 16, 2015 Accepted: February 06, $2016 \quad$ Published: February 19, 2016
}

\section{ABSTRACT}

Autophagy is a highly regulated catabolic pathway responsible for the degradation of long-lived proteins and damaged intracellular organelles. Perturbations in autophagy are found in gastric cancer. In host gastric cells, autophagy can be induced by Helicobacter pylori (or H. pylori) infection, which is associated with the oncogenesis of gastric cancer. In gastric cancer cells, autophagy has both pro-survival and pro-death functions in determining cell fate. Besides, autophagy modulates gastric cancer metastasis by affecting a wide range of pathological events, including extracellular matrix (ECM) degradation, epithelial-to-mesenchymal transition (EMT), tumor angiogenesis, and tumor microenvironment. In addition, some of the autophagy-related proteins, such as Beclin 1, microtubule-associated protein 1 light chain 3 (MAP1-LC3), and p62/sequestosome 1 (SQSTM1) have certain prognostic values for gastric cancer. In this article, we review the recent studies regarding the functional role of autophagy in gastric cancer.

\section{INTRODUCTION}

Gastric cancer is a prevalent digestive tract tumor and one of the leading causes of cancer-related death worldwide. According to the estimates from the International Agency for Research on Cancer (IARC) in 2012, 951,600 cases are newly diagnosed as gastric cancer and this disease contributes to 723,100 deaths [1]. Host-associated factors as well as environmental factors contribute to disease development [2], among which the chronic Helicobacter pylori (or H. pylori) infection is considered as a major risk factor for tumorigenesis [3]. However, the molecular mechanisms involved in the oncogenesis and progression of gastric cancer have not yet been fully understood.

Autophagy, an intracellular homeostatic pathway, is highly conserved from yeast to human. By degradation of intracellular materials, autophagic process provides cells energy under nutrient-depleted conditions or upon various cellular stresses. According to this view, autophagy serves as a self-defensive pathway which benefits tumor cell survival under extraordinary circumstance by preventing the accumulation of garbage or toxins [4, 5]. However, aberrant autophagic activity may result in the inappropriate degradation of proteins and organelles that are indispensible for maintaining tumor cell survival, and ultimately lead to autophagic cell death [6]. Growing evidence reveals the vital role of autophagy in many physiopathological processes of human diseases, including neurodegenerative diseases [7], vascular disorders [8], inflammation [9], as well as cancer [10].

In this article, we review the recent studies regarding the involvement of autophagy in the tumorigenesis and progression of gastric cancer. The potential clinical significance of autophagy-related proteins in predicting the prognosis of gastric cancer is also discussed. Understanding the functional role of autophagy in modulating gastric cancer pathogenesis allows us to harness this process for improving the disease management.

\section{AN OVERVIEW OF AUTOPHAGY}

Depending on the choice of path by which cargo 
is delivered into lysosome, autophagy is categorized into three forms, macroautophagy, microautophagy and chaperone-mediated autophagy (CMA) [11]. Macroautophagy is a process by which the aggregated proteins or damaged intracellular organelles are encapsulated into a double-membrane structure termed autophagosome, which fuses with lysosomes for protein and organelle degradation [12] (Figure 1). Microautophagy is characterized by the direct engulfment of cytoplasmic cargo by the invagination of lysosomal membrane followed with the delivery of the contents into the lysosomal lumen [13]. Both macroautophagy and microautophagy can be selective and non-selective. Nonselective autophagy is responsible for the degradation of the bulk cytoplasm (Figure 1). According to the unique substrate that delivered, selective autophagy is termed as mitophagy for mitochondrial turnover [14], ER-phagy for endoplasmic reticulum (ER) $[15,16]$, lysophagy for lysosomes [17], proteaphagy for proteasomes [18], nucleophagy for nucleus [16], xenophagy for microbes (bacteria and viruses) [19, 20] (Figure 1). CMA is a selective lysosomal degradative pathway in which cytosolic proteins are delivered to lysosomes for degradation by molecular chaperones [21]. As macroautophagy is accepted as the most universal subtype of autophagy and is known to be involved in the human cancer, in this review we mainly discuss the interaction between macroautophagy (hereafter autophagy) and gastric cancer. The autophagic process involves a series of steps with multiple autophagy-related genes (Atgs) and signaling pathways participated in the core machinery of autophagy [22].

\section{AUTOPHAGY IN ONCOGENESIS OF GASTRIC CANCER}

\section{Autophagy and Helicobacter pylori in gastric cancer}

Infection of H. pylori, a Gram-negative bacterial pathogen, is considered as a major etiological factor for the gastric carcinogenesis [23]. H. pylori virulence factors, such as vacuolating cytotoxin ( $\operatorname{VacA})$ and cytotoxinassociated gene $\mathrm{A}(\mathrm{Cag} \mathrm{A})$, contribute to the development of gastric cancer [24]. Emerging lines of evidence suggest that several microorganisms, including $H$. pylori, can be eliminated through an autophagy-dependent degradative pathway known as xenophagy [20]. Moreover, individuals with the $\operatorname{atg} 16 L 1$ (mammalian Atg16 homologue) risk allele have increased risks to infection [25]. It appears that autophagy is linked to the host susceptibility to $H$. pylori infection.

The association between autophagy and $H$. pylori infection in host cells is multifaceted [26]. Accumulating evidence indicates that $H$. pylori is capable of inducing autophagy in both gastric epithelial cells [27] and professional phagocytes, such as macrophages [28]. In gastric epithelial cells, virulence factor VacA is required for the formation of autophagosomes, and the activation of autophagy in response to VacA exposure in turn limits the toxin-induced host cell damage by degrading VacA [27, 29]. Silencing of the autophagy-related protein Atg12 leads to increased VacA level in infected cells [27]. In agreement with this finding, blockage of autophagy by 3-methyladenine favors the intracellular replication and survival of $H$. pylori, while autophagy stimulator rapamycin promotes bacterial clearance in gastric epithelial cells [30]. These observations point towards the possibility that autophagy may serve as a selfdefensive pathway against toxin exposure. In contrast, prolonged exposure of gastric epithelial cells to VacA causes disturbance in autophagy, and consequently results in the excessive production of reactive oxygen species (ROS) and the accumulation of autophagic substrate p62/ sequestosome 1 (SQSTM1) [25]. ROS governs the human tumorigenesis through driving DNA mutation [31]. Severe DNA lesion or defective DNA repair capacity, induced by chronic oxidative stress, promotes the disease progression from infection to gastric cancer [32]. The overexpression of the oncoprotein p62/SQSTM1, caused by autophagy defects, has been found to promote tumorigenesis

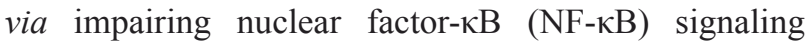
transduction pathway [33]. In this regard, it is speculated that autophagy in host cells has varied responses to acute and chronic virulence factor exposure.

Unlike VacA, which is necessary and sufficient for the autophagosome formation in gastric epithelial cells, CagA seems to be dispensable for autophagy induction [27]. According to Tsugawa's report [34], VacA activates the autophagic degradation of CagA in host gastric epithelial cells. Interestingly, CagA predominantly accumulates in CD44-positive gastric cancer stem-like cells by escaping from autophagic degradation [34]. The CD44 expression can be induced upon chronic inflammation [35]. Considering the CD44-exresssing cancer stem cells might be developed from normal gastric epithelial cells upon chronic $H$. pylori infection, CagA is more likely to participate in a later stage, rather than early stage of gastric carcinogenesis.

Systemic reviews regarding the $H$. pylori-modulated autophagy in gastric cancer can be found elsewhere [36, 37].

\section{Atgs in tumorigenesis of gastric cancer}

The implication of some autophagy-related proteins in gastric cancer is summarized in Table 1. Beclin 1 (mammalian homologue of yeast Atg6) and microtubuleassociated protein 1 light chain 3 (MAP1-LC3 or LC3, mammalian homologue of yeast Atg8) are involved in the 
Table 1: Autophagy-related proteins and their functions in gastric cancer

\begin{tabular}{|c|c|c|}
\hline Protein & Function in autophagic machinery & Function in gastric cancer \\
\hline Atg2 & Required for autophagosome formation [106] & Frameshift mutations in atg $2 B$ are common in gastric cancers with high MSI [45] \\
\hline $\operatorname{Atg} 5$ & $\begin{array}{l}\text { Coupled with Atg12 to form an Atg12-Atg5 } \\
\text { conjugate, which is involved in phagophore } \\
\text { expansion [107] }\end{array}$ & $\begin{array}{l}\text { Frameshift mutations in atg } 5 \text { are common in gastric cancers with high MSI [45]. } \\
\text { Absent in approximately one fifth of the gastric cancers [44], but is highly expressed } \\
\text { in chemoresistant gastric cancer cells [72]. Associates with the shorter survival time in } \\
\text { gastric cancer patients [72] }\end{array}$ \\
\hline Atg6/Beclin 1 & $\begin{array}{l}\text { A component of the class III PI3K complex } \\
\text { that contributes to the biosynthesis of } \\
\text { phagophore and autophagosomes [107] }\end{array}$ & $\begin{array}{l}\text { Upregulated in gastric cancer tissues }[38-40] \text { and several gastric cancer cell lines }[41,42] \text {. } \\
\text { Increased Beclin } 1 \text { expression predicts a more favorable prognosis }[41,95,96]\end{array}$ \\
\hline Atg8/LC3 & $\begin{array}{l}\text { Involved in the cargo recruitment into, and the } \\
\text { biosynthesis of autophagosomes [107] }\end{array}$ & $\begin{array}{l}\text { Upregulation of LC3 correlates } \mathrm{Ki}-67 \text { in gastrointestinal cancers [99]. The number of } \\
\text { LC3-positive puncta predicts poor prognosis of gastric cancer [100] }\end{array}$ \\
\hline Atg9 & $\begin{array}{l}\text { Acts as a lipid carrier for phagophore } \\
\text { expansion [107] }\end{array}$ & Frameshift mutations in $\operatorname{atg} 9 B$ are common in gastric cancers with high MSI [45] \\
\hline $\operatorname{Atg} 12$ & $\begin{array}{l}\text { Coupled with Atg5 to form an Atg12-Atg5 } \\
\text { conjugate, which is involved in phagophore } \\
\text { expansion [107] }\end{array}$ & $\begin{array}{l}\text { Frameshift mutations in } \operatorname{atg} 12 \text { are common in gastric cancers with high MSI [45]. } \\
\text { Contributes to autophagy-mediated degradation of virulence factor VacA in gastric } \\
\text { epithelial cells [27] }\end{array}$ \\
\hline $\operatorname{Atg} 16$ & $\begin{array}{l}\text { Associates with Atg12-Atg5 conjugate and } \\
\text { participates in phagophore expansion [107] }\end{array}$ & $\begin{array}{l}\text { Individuals with the atg } 16 L 1 \text { risk allele have increased risks to } H \text {. pylori infection [25]. } \\
\text { Negatively expressed in gastric cancer [40] }\end{array}$ \\
\hline AMPK & $\begin{array}{l}\text { An important cellular energy sensor that is able } \\
\text { to activate autophagic process }[81,82]\end{array}$ & $\begin{array}{l}\text { Acts a pro-survival role for cancer cells during ECM detachment by inhibiting mTOR } \\
\text { and activating autophagy }[81,83,84]\end{array}$ \\
\hline Bcl-2 & $\begin{array}{l}\text { A member of the Bcl-2 family; negatively } \\
\text { regulates autophagy by interacting with Beclin } \\
1 \text { [108] }\end{array}$ & $\begin{array}{l}\text { Modulates both autophagy and apoptosis pathways during gastric cancer cell death [75], } \\
\text { and is a prognostic factor of survival in gastric cancer patients [93] }\end{array}$ \\
\hline mTOR & $\begin{array}{l}\text { A protein kinase that negatively modulates } \\
\text { macroautophagy [107] }\end{array}$ & $\begin{array}{l}\text { Blockage of mTOR activates autophagy, which subsequently favors cancer cell survival } \\
\text { during ECM detachment }[83,84]\end{array}$ \\
\hline p62/SQSTM1 & $\begin{array}{l}\text { An ubiquitin binding protein that serves as a } \\
\text { selective autophagy substrate [116] }\end{array}$ & $\begin{array}{l}\text { Upregulated in gastric cancer; increased p62/SQSTM1 level associates with poor } \\
\text { differentiation and reduced lymph node metastasis of gastric cancer [102] }\end{array}$ \\
\hline SIRT1 & $\begin{array}{l}\text { Drives the initiation of autophagy via } \\
\text { deacetylation of Atgs, such as LC3 [89] }\end{array}$ & $\begin{array}{l}\text { Upregulated in tumor tissues and correlates with advanced lymph node metastasis in } \\
\text { gastric cancer [87]. Regulates EMT and invasion capability of gastric cancer cells [88] }\end{array}$ \\
\hline
\end{tabular}

AMPK, AMP-activated protein kinase; Atg, autophagy-related gene; Bcl-2, B-cell lymphoma-2; ECM, extracellular matrix; EMT, epithelial-to-mesenchymal transition; LC3, microtubule-associated protein 1 light chain 3; mTOR, mammalian target of rapamycin; MSI, microsatellite instability; PI3K, phosphatidylinositol 3-kinase; SQSTM1, sequestosome 1; SIRT1, silent mating type information regulation 1 .

biosynthesis of the autophagosome, which is the initial step of autophagy. Increased Beclin 1 [38-40] and LC3-I/ II conversion [39] was detected in human gastric cancer tissues. Upregulated Beclin $1 \mathrm{mRNA}$ and protein is also noted in several gastric cancer cell lines, as compared with that in normal gastric mucosa cell line (GES-1) [41, 42]. Using immunohistochemical analysis, the distribution of Beclin 1 is mainly found in cytoplasm of tumor cells. The point mutation of beclin 1 rarely occurs in common human cancers. According to Lee's report, only 2.8\% (5/180) of the gastric cancer samples harbor beclin 1 gene mutation [43]. Concomitantly, the somatic mutation of atg5 is presented in gastric cancers although the incidence is quite low $(1.5 \% ; 2 / 135)[44]$. It should be noted that the protein expression of Atg5 is lost in $21.0 \%(21 / 100)$ of the gastric cancers [44]. In another study, Vigen et al. reported an extremely high negative expression of Atg5 and Atg16 in patients with gastric adenocarcinoma (Atg5, 80.0\%, 8/10; Atg16, 80.0\%, 8/10) or gastric carcinoid (Atg5, 60.0\%, $6 / 10$; Atg16, 90.0\%, 9/10) [40]. Considering the number of samples is relatively small, further integrative work would be required by including considerably larger sample size. Nevertheless, the loss of expression or mutation of these atgs may participate in the tumorigenesis and progression of gastric cancer possibly via altering the autophagic cell death.

Using single-strand conformation polymorphism analysis, Kang et al. revealed that the frameshift mutations in atg genes with mononucleotide repeats, including $\operatorname{atg} 2 B$ (mammalian atg2 homologue), atg5, atg9B (mammalian atg9 homologue), and atg12, were common in gastric cancers with high microsatellite instability (MSI) subtypes $(28.1 \%$; 9/32), while mutations were not detected in patients with low MSI [45]. In addition, the frameshift mutations of ultraviolet radiation resistance-associated gene (UVRAG), which binds to Beclin 1 and triggers autophagy activation, is also found in gastric cancers with high MSI $(9.4 \% ; 3 / 32)$ [46]. These evidence suggest that the autophagic route might be perturbed especially in gastric cancers with high MSI. Identification of crystal structure of Atg family proteins or complex may provide an essential molecular basis for understanding the unique role of Atgs in the oncogenesis of gastric cancer.

\section{Pro-death and pro-survival role of autophagy in gastric cancer}

Autophagy is considered to play a tumor suppressive function by leading cells to autophagic death [47]. This augment has been supported by numerous evidence [48, 49]. Indeed, autophagic cell death, but not apoptotic cell death, has been documented in gastric cancer death induced by different pharmacological treatments [50, 
51]. In contrast, the concurrent induction of autophagy and apoptosis has been documented in gastric cancer cell in a number of studies [52-57]. Although varies largely in molecular mechanisms, the autophagic and apoptotic machinery talk to each other in many aspects [58]. The pattern of crosstalk between autophagy and apoptosis are worthy of consideration here. First, autophagy and apoptosis may govern gastric cell fate in parallel and independent routes. Interestingly, autophagic and apoptotic cell death pathway depends largely on the status of cell and the intracellular signaling environment, as wild type or drug resistant gastric cancer cells may decide to undergo apoptotic and autophagic cell death, respectively [59]. Second, autophagy may execute cell death with apoptosis in a cooperative manner [60]. In support of such hypothesis, $\mathrm{Xu}$ et al. showed that the anti-cancer drug akebia saponin PA resulted in both autophagic and apoptotic cell death in gastric cancer AGS cells [61]. Autophagy blockage suppressed the apoptosis-related caspase-3 activation, while inhibition of caspase- 3 had no influences on autophagic pathway [61]. Relevantly, a recent report showed that disturbance of p62/SQSTM1, the autophagy adaptor, led to cargo loading failure, converted the cytoprotective clearance into insufficient autophagic degradation, and ultimately resulted in cell apoptosis [62]. Hence, it is possible that both autophagy and apoptosis modulate cell death independently, and autophagy lies on the upstream of apoptosis and is required for apoptotic cell death.

In the second scenario, autophagy acts as an oncogenetic pathway that favors tumor cell survival. The addition of autophagy inhibitor, such as chloroquine and bafilomycin A1, sensitizes the cytotoxicity of anticancer drugs in gastric cancer cells [63-68], indicating the autophagy inhibitor might be a favorable candidate for the chemotherapy of gastric cancer. The specific mechanism underlying the pro-survival function of autophagy remains largely unknown. One study has indicated that autophagy antagonizes apoptotic cell death in gastric cancer cells through mediating high-mobility group box-1 (HMGB1) release into the extracellular milieu [69]. Another issue important to consider is the chemoresistance in gastric cancer [70]. Recently, emerging lines of evidence highlight the involvement of autophagy in chemoresistance of gastric cancer. Apparent overactivation of autophagy is observed in chemoresistant

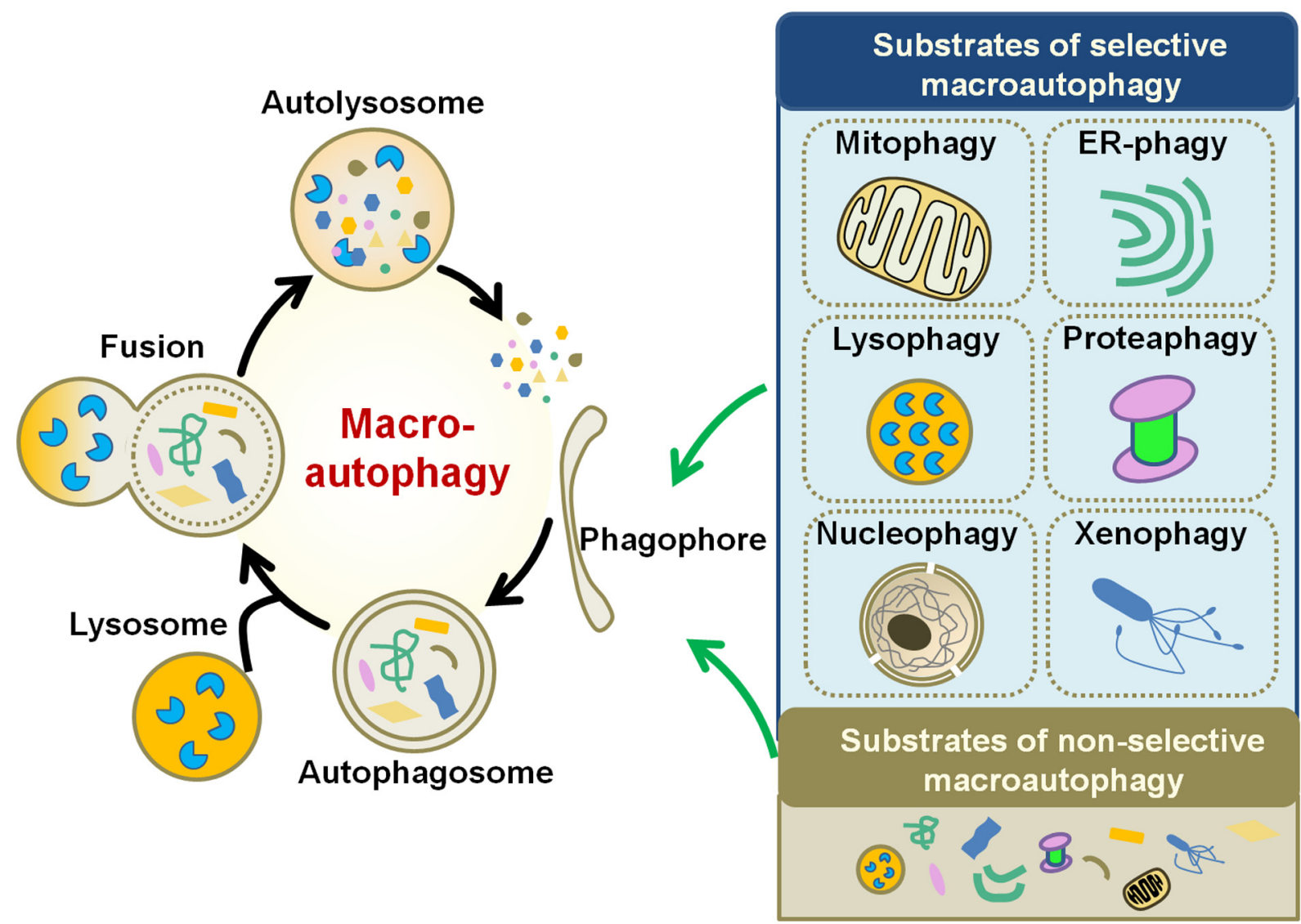

Figure 1: Schematic diagram of macroautophagy. Macroautophagy initiates by the formation of phagophore, which sequesters specific cargoes (selective macroautophagy) or bulk cytoplasm (non-selective macroautophagy) into an autophagosome. Fusion of the autophagosome with lysosome results in the degradation of the cargoes. Upon the induction of selective autophagy, the cargoes can be mitochondria (for mitophagy), ER (ER-phagy), lysosomes (lysophagy), proteasomes (proteaphagy), nucleus (nucleophagy), or microbes (xenophagy). 
gastric cancer cell line, whereas autophagy blockage by chloroquine significantly enhances the chemosensitivity of cells [71]. Consistent with this notion, sustained expression of Atg5 is detected in chemoresistant gastric cancer cell line, and downregulation of Atg 5 sensitizes chemoresistant cells to drug therapy [72]. Given the fact that autophagy ensures the survival of gastric cancer cells that are resistant to chemotherapy, drug resistance, the major problem of chemotherapy associated with poor chemotherapy responses and prognosis, might be solved by autophagy inhibition [73].

Taken collectively, autophagy is a double-edged sword for gastric cancer. The pro-death (tumor suppressor) and pro-survival (tumor promoter) role of autophagy is particularly associated with its interaction of apoptosis. It is unclear, however, whether the indentified points of convergence between two pathways [74] also regulate these cell-death machineries in gastric cancer cells. Study about the impact of convergent points or molecular switch nodes, such as B-cell lymphoma-2 (Bcl-2) family members [75], in deciding the fate of gastric cancer cells, may provide new clue to unmask the crosstalk between autophagy and apoptosis in oncogenesis.

\section{AUTOPHAGY IN GASTRIC CANCER PROGRESSION}

Tumor metastasis, at the site of distant tissues or organs, is a sign predicting advanced progression and poor prognosis of gastric cancer [76]. The process of tumor metastasis is complex, involving a series of pathological events such as the breakdown of extracellular matrix (ECM), epithelial-to-mesenchymal transition (EMT), tumor angiogenesis, tumor microenvironment formation, etc [77]. The role of autophagy in tumor metastasis is believed to be both pro-metastatic and anti-metastatic [77]. Regarding gastric cancer, although autophagic cell death may inhibit metastasis, most of the current findings supports the notion that autophagy facilitate tumor metastasis through affecting several aspects (Figure 2).

\section{ECM degradation}

Matrix metalloproteinase (MMP) proteins gain widespread attention because of their principle roles in the modulation of ECM degradation, paving the way for tumor cell metastasis [78]. In disseminated gastric cancer NUGC4 cells, treatment of chemokine CXCL12 resulted in an increased production of MMP and augmented cell migration through activating the mammalian target of rapamycin (mTOR) pathway [79]. It should be noted that $\mathrm{mTOR}$ is considered as a negative regulator of autophagic machinery. Under nutrient-rich condition, mTOR suppresses autophagy by inhibiting Atg13 and Atg1 (ULK1/2) complex, while blockage of mTOR upon nutrient starvation or stress launches autophagy in eukaryotes [80]. According to Hashimoto's report [79], inhibition of mTOR signal by rapamycin prevented the MMP generation, inhibited cell migration, and led to autophagic cell death in NUGC4 cells. In addition to pharmacological interference, enforced mTOR inhibition can be resulted from several upstream signals, such as the cellular energy sensor AMPK [81, 82]. Blockage of mTOR by AMPK triggers autophagy, which acts a prosurvival role for cancer cells during ECM detachment $[83,84]$. The enhanced autophagic process prevents ECM detached cells from anoikis and contributes to luminal filling possibly by providing sustained ATP source [83, 84]. Hence, in the early stage of progression, autophagy might be an adaptive strategy for the detached cancer cells to overcome anoikis [85] (Figure 2A).

\section{EMT}

Highly upregulated in liver cancer (HULC), a long non-coding RNA (lncRNA), is found to be overexpressed in gastric cancer cell lines as well as in gastric cancer tissues when compared to control [86]. Moreover, the increased HULC expression contributes to enhanced EMT phenotype and invasion in SGC-7901 cells by inducing LC3-II formation and autophagy induction [86], implying the involvement of autophagy in tumor metastasis. Similar to that of HULC, silent mating type information regulation 1 (SIRT1), a class III histone deacetylase, is also upregulated in tumor tissues and correlates with advanced lymph node metastasis in gastric cancer [87]. In vitro study further confirmed the regulatory effects of SIRT1 in EMT and invasion capability of gastric cancer cells [88]. Importantly, SIRT1 is a well characterized autophagy mediator, which drives the initiation of autophagy via deacetylation of Atgs, such as LC3 [89]. Based on the evidence, autophagic process, modulated by SIRT1 or other mediators may play a central role in tumor progression by regulating EMT and tumor cell invasion [90] (Figure 2B). Perturbation of autophagic activity may be a potential strategy for controlling tumor invasion.

\section{Tumor angiogenesis}

Vasculogenic mimicry, a novel pattern of tumor angiogenesis, plays an essential role in the growth and metastasis of cancer by providing oxygen and nutrient supplementation [91]. Using a three-dimensional culture system in which gastric cancer SGC-7901 cells were maintained on Marigel matrix, Ding et al. [92] reported that autophagy promoted the survival and invasive ability of SGC-7901 cells by facilitating the formation of vasculogenic mimicry. Inhibition of autophagy by silencing of Beclin 1 expression reduced the cancer cell survival and invasion [92]. Hence, Beclin 1-dependent 
autophagy might be required for tumor angiogenesis of gastric cancer (Figure 2C). As tumor angiogenesis is in high nutrient and energy demands, autophagy supports bioenergetic demands by digesting and recycling of intracellular materials. Pharmacological inhibition of autophagy together with anti-angiogenic therapy merges as a promising way for overcoming tumor angiogenesis.

\section{Tumor microenvironment}

Autophagy is an adaptive response to stress, and can be induced by a variety of stimuli. Regarding the tumor microenvironment, autophagy is a consequence rather than cause, that can be robustly induced by hypoxia, nutrient depletion, and inflammation [5]. Activated autophagy, in turn, shapes the tumor microenvironment by promoting tumor angiogenesis, providing nutrient supply, and regulating inflammatory responses [4, 5] (Figure 2D). Nonetheless, evidence regarding the involvement of autophagy during the formation of tumor microenvironment in gastric cancer is quite limited, and the precise role of autophagy in shaping tumor microenvironment still needs to be further clarified.

\section{Prognostic value of autophagy-related proteins in gastric cancer}

Several molecular markers have been identified to possess prognostic value for gastric cancer, including MSI, growth factors (e.g. human epidermal growth factor receptor-2 [HER-2], epidermal growth factor receptor [EGFR], vascular endothelial growth factor [VEGF], etc.), cytokines (e.g. interleukin [IL]-11, IL-6), cell cycle mediators (e.g. cyclin E), apoptosis-associated regulators (e.g. Bcl-2, Fas, survivin), microRNAs (e.g. microRNA [miR]-21, microRNA-214, microRNA-433, etc.) [93]. Of greater concern is the accuracy and specificity of these biomarkers for delineating disease prognosis. Here, we mainly discuss the prognostic impact of three principle modulators in autophagy process.

Beclin 1 functions as a scaffold for the formation of phosphatidylinositol 3 kinase (PI3K) complex, which is an initial step for autophagosome formation. Binding

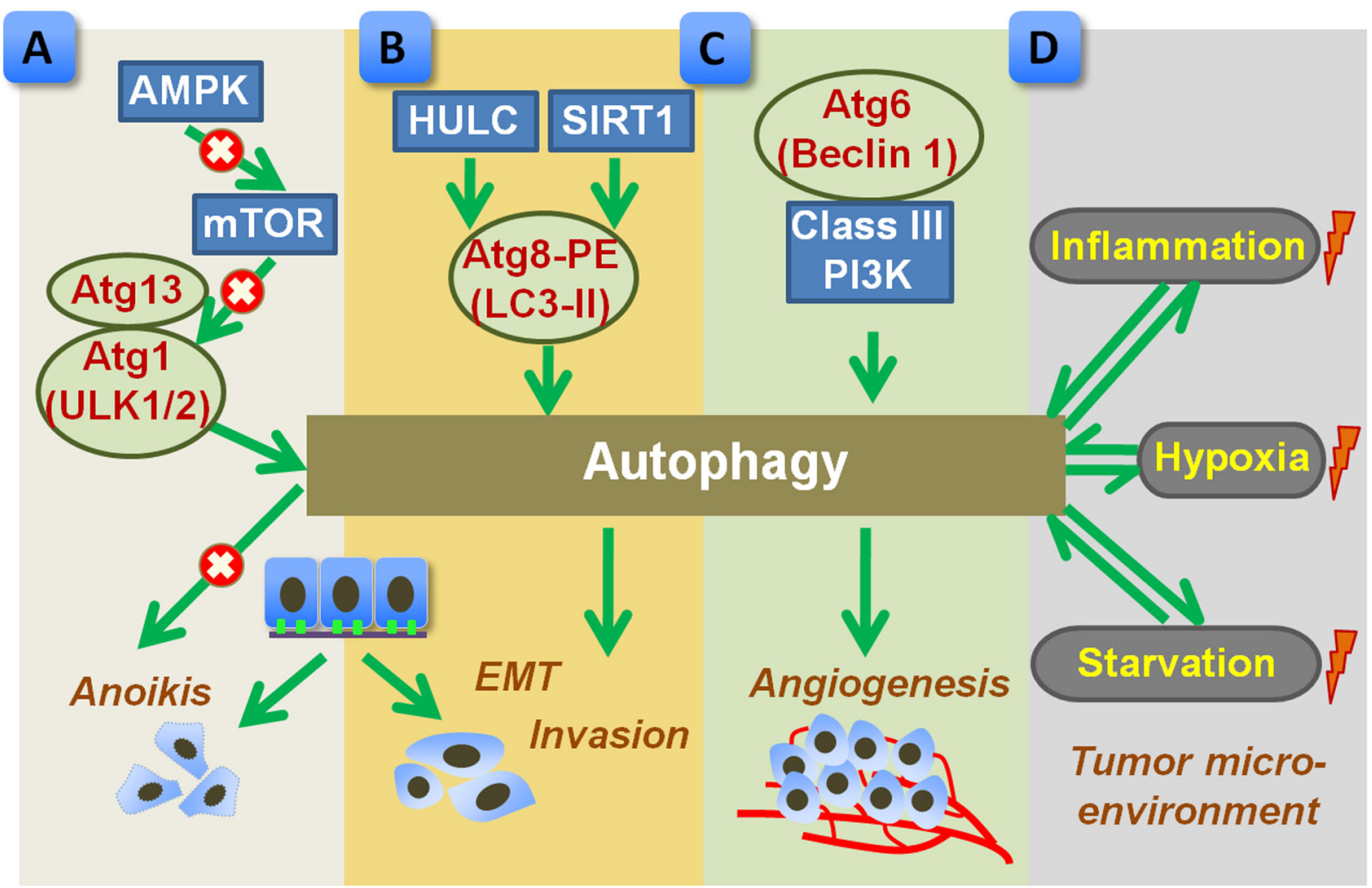

Figure 2: Proposed role of autophagy in promoting metastasis of gastric cancer. A. Autophagy, regulated by AMPK-mTOR signal pathway, benefits the detached cancer cells to overcome anoikis. mTOR negatively regulates autophagy by inhibiting Atgs such as Atg13 and Atg1 (ULK1/2). B. Upstream factors, such as SIRT1 or HULC, trigger autophagic activation by inducing Atg8 and PE conjugation (LC3-II formation), which subsequently promotes EMT and tumor invasion. C. Autophagy, regulated by Atg6 (Beclin 1) and class III PI3K, enhances tumor angiogenesis. D. Tumor microenvironment, such as hypoxia, starvation, and inflammation, may influence autophagic process, which in turn shapes tumor microenvironment. The autophagy related proteins were highlighted in red. Arrow indicates a stimulatory effect and $\times$ indicates an inhibitive effect. AMPK, AMP-activated protein kinase; EMT, epithelial-to-mesenchymal transition; HULC, highly upregulated in liver cancer; LC3, microtubule-associated protein 1 light chain 3; mTOR, mammalian target of rapamycin; PE, phosphatidylethanolamine; PI3K, phosphatidylinositol 3-kinase; SIRT1, silent mating type information regulation 1. 
of Bcl-2 family members (e.g. Bcl-2 and Bcl-xL) to Beclin 1 suppresses the induction of Beclin 1-dependent autophagy [94]. A Chinese study indicates that the level of Beclin 1 is closely correlated to the clinicopathologic characteristics of gastric cancer, including gender, age, and the histological subtype of tumor [41]. However, another Korean study shows that the Beclin 1 level is not correlated with the clinicopathologic properties of patients with gastric cancer, including metastasis, invasion, and stage [38]. Such discrepancy might be attributed to the geographical diversities or the small sample size studied. It may be fruitful to adopt larger sample size in future study. Beclin 1 is identified as an independent prognostic factor for gastric cancer $[41,95,96]$. Beclin 1 expression is negatively correlated with the poor tumor differentiation, tumor metastasis, advanced tumor-nodemetastasis (TNM) stage, tumor recurrence as well as shorter survival in gastric cancer patients [41, 96, 97]. Consistently, decreased Beclin 1 level, closely associated with upregulated Bcl-xL expression, predicts increased malignant phenotype and poor prognosis of gastric cancer $[95,97]$. In the patients with node-positive gastric cancer, Beclin 1 level is significantly associated with intravascular embolus and positively correlated to longer survival [42]. Based on these observations, increased Beclin 1 expression predicts a more favorable prognosis. Indeed, autophagy allows prolonged survival [98], making it amenable to explaining patient with reduced Beclin 1 expression have poor prognosis.

Increased number of LC3-positive puncta can be found in gastric cancer cells. In contrast to Beclin 1 that predicts better prognosis, in gastrointestinal cancers, upregulated LC3 expression partially correlates with the level of $\mathrm{Ki}-67$, a proliferation index associated with the clinical courses of cancer [99]. The number of LC3positive puncta is positively associated with the risks of tumor relapse after radical resection in patients with stage I-III gastric cancer, and negatively correlated to the overall survival rate for patients at stage IV [100]. Thus, the presence of LC3-positive puncta is proposed to be another independent biomarker predicting poor prognosis of gastric cancer [100]. The observation of accumulated LC3-positive puncta may be better explained in terms of impairments in autophagic degradation rather than enhancement of autophagic activity.

p62/SQSTM1, an ubiquitin binding protein, serves as a selective autophagy substrate [101]. The degradation of p62/SQSTM1 reflects the turnover of autophagy machinery, and defective autophagy results in abundant p62/SQSTM1 accumulation. The expressions of both p62/SQSTM1 and ubiquitin are very weak in normal gastric tissue samples, while increased nuclear and cytoplasmic expression of both proteins are detected in gastric cancers [102]. Moreover, the increased expression of p62/SQSTM1 is found to be associated with poor differentiation and reduced lymph node metastasis of gastric cancer [102]. This pattern of results concur with the notion that autophagy defect results in the insufficient degradation of p62/SQSTM1, which ultimately leads to tumorigenesis by dysregulating $N F-\kappa B$ signaling transduction pathway and gene expression modulation [33].

\section{CONCLUSIONS}

Despite the studies on autophagy and gastric cancer have merged in the recent years, we are still at the very initial stages of understanding the complicated regulatory role of autophagy in the oncogenesis, progression and prognosis of this malignancy. Apoptosis is not the sole route of programmed cell death (PCD), but interacts with autophagy to execute gastric cancer cell death. In this regard, manipulation of autophagy has been proven to sensitize cancer cells to chemotherapy. However, autophagy can be more beneficial, rather than destructive, to enable cancer cell survival by providing energy. Given the dual role of autophagy in gastric cancer, it seems that the activation of autophagy should be maintained at a moderate degree. Nowadays, the development of molecules and pharmacologic agents targeting autophagy attracts increasing attentions and the autophagy inducers as well as inhibitors are currently under development for clinical use [103-105]. Interference of autophagic process may offer a novel strategy for controlling tumorigenesis and progression of gastric cancer.

\section{ACKNOWLEDGMENTS}

This work was supported by grants from National Natural Science Foundation of China (81401043), Zhejiang Provincial Natural Science Foundation of China (LQ13H310004), and Science Foundation of Hangzhou Normal University (2012QDL048).

\section{CONFLICTS OF INTEREST}

The authors declare no conflicts of interest.

\section{REFERENCES}

1. Torre LA, Bray F, Siegel RL, Ferlay J, Lortet-Tieulent J and Jemal A. Global cancer statistics, 2012. CA Cancer J Clin. 2015; 65:87-108.

2. Tan P and Yeoh KG. Genetics and molecular pathogenesis of gastric adenocarcinoma. Gastroenterology. 2015; 149:1153-1162.

3. Plummer M, Franceschi S, Vignat J, Forman D and de Martel C. Global burden of gastric cancer attributable to Helicobacter pylori. Int J Cancer. 2015; 136:487-490.

4. Maes H, Rubio N, Garg AD and Agostinis P. Autophagy: shaping the tumor microenvironment and therapeutic 
response. Trends Mol Med. 2013; 19:428-446.

5. Yang X, Yu DD, Yan F, Jing YY, Han ZP, Sun K, Liang L, Hou J and Wei LX. The role of autophagy induced by tumor microenvironment in different cells and stages of cancer. Cell Biosci. 2015; 5:14.

6. Levine B and Kroemer G. Autophagy in the pathogenesis of disease. Cell. 2008; 132:27-42.

7. Menzies FM, Fleming A and Rubinsztein DC. Compromised autophagy and neurodegenerative diseases. Nat Rev Neurosci. 2015; 16:345-357.

8. De Meyer GR, Grootaert MO, Michiels CF, Kurdi A, Schrijvers DM and Martinet W. Autophagy in vascular disease. Circ Res. 2015; 116:468-479.

9. Netea-Maier RT, Plantinga TS, Van De Veerdonk FL, Smit JW and Netea MG. Modulation of inflammation by autophagy: consequences for human disease. Autophagy. 2016; 12:245-60.

10. Jiang X, Overholtzer $M$ and Thompson CB. Autophagy in cellular metabolism and cancer. J Clin Invest. 2015; 125:4754.

11. Mizushima N and Komatsu M. Autophagy: renovation of cells and tissues. Cell. 2011; 147:728-741.

12. Yang $Z$ and Klionsky DJ. Eaten alive: a history of macroautophagy. Nat Cell Biol. 2010; 12:814-822.

13. Li WW, Li J and Bao JK. Microautophagy: lesser-known self-eating. Cell Mol Life Sci. 2012; 69:1125-1136.

14. Kim I, Rodriguez-Enriquez S and Lemasters JJ. Selective degradation of mitochondria by mitophagy. Arch Biochem Biophys. 2007; 462:245-253.

15. Khaminets A, Heinrich T, Mari M, Grumati P, Huebner AK, Akutsu M, Liebmann L, Stolz A, Nietzsche S, Koch N, Mauthe M, Katona I, Qualmann B, Weis J, Reggiori F, Kurth I, et al. Regulation of endoplasmic reticulum turnover by selective autophagy. Nature. 2015; 522:354-358.

16. Mochida K, Oikawa Y, Kimura Y, Kirisako H, Hirano H, Ohsumi Y and Nakatogawa H. Receptor-mediated selective autophagy degrades the endoplasmic reticulum and the nucleus. Nature. 2015; 522:359-362.

17. Hasegawa J, Maejima I, Iwamoto $\mathrm{R}$ and Yoshimori $\mathrm{T}$. Selective autophagy: lysophagy. Methods. 2015; 75:128132.

18. Marshall RS, Li F, Gemperline DC, Book AJ and Vierstra RD. Autophagic Degradation of the 26S Proteasome Is Mediated by the Dual ATG8/Ubiquitin Receptor RPN10 in Arabidopsis. Mol Cell. 2015; 58:1053-1066.

19. Bauckman KA, Owusu-Boaitey $\mathrm{N}$ and Mysorekar IU. Selective autophagy: xenophagy. Methods. 2015; 75:120127.

20. Castrejon-Jimenez NS, Leyva-Paredes K, HernandezGonzalez JC, Luna-Herrera J and Garcia-Perez BE. The role of autophagy in bacterial infections. Biosci Trends. 2015; 9:149-159.

21. Dice JF. Chaperone-mediated autophagy. Autophagy. 2007;
$3: 295-299$

22. Feng $\mathrm{Y}, \mathrm{He} \mathrm{D}, \mathrm{Yao} \mathrm{Z}$ and Klionsky DJ. The machinery of macroautophagy. Cell Res. 2014; 24:24-41.

23. Megraud F, Bessede E and Varon C. Helicobacter pylori infection and gastric carcinoma. Clin Microbiol Infect. 2015; 21: 984-990.

24. Ferreira RM, Machado JC and Figueiredo C. Clinical relevance of Helicobacter pylori vacA and cagA genotypes in gastric carcinoma. Best Pract Res Clin Gastroenterol. 2014; 28:1003-1015.

25. Raju D, Hussey S, Ang M, Terebiznik MR, Sibony M, Galindo-Mata E, Gupta V, Blanke SR, Delgado A, RomeroGallo J, Ramjeet MS, Mascarenhas H, Peek RM, Correa P, Streutker C, Hold G, et al. Vacuolating cytotoxin and variants in Atg16L1 that disrupt autophagy promote Helicobacter pylori infection in humans. Gastroenterology. 2012; 142:1160-1171.

26. Deen NS, Huang SJ, Gong L, Kwok T and Devenish RJ. The impact of autophagic processes on the intracellular fate of Helicobacter pylori: more tricks from an enigmatic pathogen? Autophagy. 2013; 9:639-652.

27. Terebiznik MR, Raju D, Vazquez CL, Torbricki K, Kulkarni R, Blanke SR, Yoshimori T, Colombo MI and Jones NL. Effect of Helicobacter pylori's vacuolating cytotoxin on the autophagy pathway in gastric epithelial cells. Autophagy. 2009; 5:370-379.

28. Wang YH, Wu JJ and Lei HY. The autophagic induction in Helicobacter pylori-infected macrophage. Exp Biol Med (Maywood). 2009; 234:171-180.

29. Raju D and Jones NL. Methods to monitor autophagy in H. pylori vacuolating cytotoxin A (VacA)-treated cells. Autophagy. 2010; 6:138-143.

30. Tang B, Li N, Gu J, Zhuang Y, Li Q, Wang HG, Fang Y, Yu B, Zhang JY, Xie QH, Chen L, Jiang XJ, Xiao B, Zou QM and Mao XH. Compromised autophagy by MIR30B benefits the intracellular survival of Helicobacter pylori. Autophagy. 2012; 8:1045-1057.

31. Dizdaroglu M. Oxidatively induced DNA damage: mechanisms, repair and disease. Cancer Lett. 2012; 327:2647.

32. Hardbower DM, de Sablet T, Chaturvedi R and Wilson KT. Chronic inflammation and oxidative stress: the smoking gun for Helicobacter pylori-induced gastric cancer? Gut microbes. 2013; 4:475-481.

33. Mathew R, Karp CM, Beaudoin B, Vuong N, Chen G, Chen HY, Bray K, Reddy A, Bhanot G, Gelinas C, Dipaola RS, Karantza-Wadsworth V and White E. Autophagy suppresses tumorigenesis through elimination of p62. Cell. 2009; 137:1062-1075.

34. Tsugawa H, Suzuki H, Saya H, Hatakeyama M, Hirayama T, Hirata K, Nagano O, Matsuzaki J and Hibi T. Reactive oxygen species-induced autophagic degradation of Helicobacter pylori CagA is specifically suppressed in cancer stem-like cells. Cell Host Microbe. 2012; 12:764- 
777.

35. Ishimoto T, Oshima H, Oshima M, Kai K, Torii R, Masuko T, Baba H, Saya H and Nagano O. CD44+ slow-cycling tumor cell expansion is triggered by cooperative actions of Wnt and prostaglandin E2 in gastric tumorigenesis. Cancer Sci. 2010; 101:673-678.

36. Greenfield LK and Jones NL. Modulation of autophagy by Helicobacter pylori and its role in gastric carcinogenesis. Trends Microbiol. 2013; 21:602-612.

37. Zhang L, Sung JJ, Yu J, Ng SC, Wong SH, Cho CH, Ng SS, Chan FK and Wu WK. Xenophagy in Helicobacter pyloriand Epstein-Barr virus-induced gastric cancer. J Pathol. 2014; 233:103-112.

38. Ahn CH, Jeong EG, Lee JW, Kim MS, Kim SH, Kim SS, Yoo NJ and Lee SH. Expression of beclin-1, an autophagyrelated protein, in gastric and colorectal cancers. APMIS. 2007; 115:1344-1349.

39. Wei SH, Li W, Liu Y, Gao DK, Pan J, Gu CW and Wu HR. Disturbance of autophagy-lysosome signaling molecule expression in human gastric adenocarcinoma. Oncol Lett. 2014; 7:635-640.

40. Vigen RA, Kodama Y, Viset T, Fossmark R, Waldum H, Kidd M, Wang TC, Modlin IM, Chen D and Zhao CM. Immunohistochemical evidence for an impairment of autophagy in tumorigenesis of gastric carcinoids and adenocarcinomas in rodent models and patients. Histol Histopathol. 2013; 28:531-542.

41. Yu M, Gou WF, Zhao S, Xiao LJ, Mao XY, Xing YN, Takahashi H, Takano Y and Zheng HC. Beclin 1 expression is an independent prognostic factor for gastric carcinomas. Tumour Biol. 2013; 34:1071-1083.

42. Geng QR, Xu DZ, He LJ, Lu JB, Zhou ZW, Zhan YQ and $\mathrm{Lu}$ Y. Beclin-1 expression is a significant predictor of survival in patients with lymph node-positive gastric cancer. PLoS One. 2012; 7:e45968.

43. Lee JW, Jeong EG, Lee SH and Yoo NJ. Somatic mutations of BECN1, an autophagy-related gene, in human cancers. APMIS. 2007; 115:750-756.

44. An CH, Kim MS, Yoo NJ, Park SW and Lee SH. Mutational and expressional analyses of ATG5, an autophagy-related gene, in gastrointestinal cancers. Pathol Res Pract. 2011; 207:433-437.

45. Kang MR, Kim MS, Oh JE, Kim YR, Song SY, Kim $\mathrm{SS}$, Ahn CH, Yoo NJ and Lee SH. Frameshift mutations of autophagy-related genes ATG2B, ATG5, ATG9B and ATG12 in gastric and colorectal cancers with microsatellite instability. J Pathol. 2009; 217:702-706.

46. Kim MS, Jeong EG, Ahn CH, Kim SS, Lee SH and Yoo NJ. Frameshift mutation of UVRAG, an autophagy-related gene, in gastric carcinomas with microsatellite instability. Hum Pathol. 2008; 39:1059-1063.

47. Kroemer G and Levine B. Autophagic cell death: the story of a misnomer. Nat Rev Mol Cell Biol. 2008; 9:1004-1010.

48. Yang $\mathrm{C}$ and Pan Y. Fluorouracil induces autophagy-related gastric carcinoma cell death through Beclin-1 upregulation by miR-30 suppression. Tumour Biol. 2015 Jul 25. PMID: 26209295.

49. Hu C, Zou MJ, Zhao L, Lu N, Sun YJ, Gou SH, Xi $\mathrm{T}$ and Guo QL. E Platinum, a newly synthesized platinum compound, induces autophagy via inhibiting phosphorylation of mTOR in gastric carcinoma BGC-823 cells. Toxicol Lett. 2012; 210:78-86.

50. Ji D, Zhang Z, Cheng L, Chang J, Wang S, Zheng B, Zheng R, Sun Z, Wang C, Liu R, Zhang X, Liu X, Wang X and Li J. The combination of RAD001 and MK-2206 exerts synergistic cytotoxic effects against PTEN mutant gastric cancer cells: involvement of MAPK-dependent autophagic, but not apoptotic cell death pathway. PLoS One. 2014; 9:e85116.

51. Huo J, Qin F, Cai X, Ju J, Hu C, Wang Z, Lu W, Wang $\mathrm{X}$ and Cao P. Chinese medicine formula "Weikang Keli" induces autophagic cell death on human gastric cancer cell line SGC-7901. Phytomedicine. 2013; 20:159-165.

52. Lee HW, Jang KS, Choi HJ, Jo A, Cheong JH and Chun KH. Celastrol inhibits gastric cancer growth by induction of apoptosis and autophagy. BMB Rep. 2014; 47:697-702.

53. Liu M, Li CM, Chen ZF, Ji R, Guo QH, Li Q, Zhang HL and Zhou YN. Celecoxib regulates apoptosis and autophagy via the PI3K/Akt signaling pathway in SGC-7901 gastric cancer cells. Int J Mol Med. 2014; 33:1451-1458.

54. Lim SC, Parajuli KR, Duong HQ, Choi JE and Han SI. Cholesterol induces autophagic and apoptotic death in gastric carcinoma cells. Int J Oncol. 2014; 44:805-811.

55. Xie B, Zhou J, Shu G, Liu DC, Chen J and Yuan L. Restoration of klotho gene expression induces apoptosis and autophagy in gastric cancer cells: tumor suppressive role of klotho in gastric cancer. Cancer Cell Int. 2013; $13: 18$.

56. Liu XY, Lv TH, Xie XD, Li J, Su G and Wu H. Antitumour effect of sesquiterpene (+)-chabranol on four human cancer cell lines by inducing apoptosis and autophagy. J Int Med Res. 2012; 40:1644-1653.

57. Rasul A, Yu B, Zhong L, Khan M, Yang H and Ma T. Cytotoxic effect of evodiamine in SGC-7901 human gastric adenocarcinoma cells via simultaneous induction of apoptosis and autophagy. Oncol Rep. 2012; 27:1481-1487.

58. Gump JM and Thorburn A. Autophagy and apoptosis: what is the connection? Trends Cell Biol. 2011; 21:387-392.

59. Lim SC and Han SI. Ursodeoxycholic acid effectively kills drug-resistant gastric cancer cells through induction of autophagic death. Oncol Rep. 2015; 34:1261-1268.

60. Eisenberg-Lerner A, Bialik S, Simon HU and Kimchi A. Life and death partners: apoptosis, autophagy and the crosstalk between them. Cell Death Differ. 2009; 16:966-975.

61. Xu MY, Lee DH, Joo EJ, Son KH and Kim YS. Akebia saponin PA induces autophagic and apoptotic cell death in AGS human gastric cancer cells. Food Chem Toxicol. 2013; 59:703-708. 
62. Chen S, Zhou L, Zhang Y, Leng Y, Pei XY, Lin H, Jones R, Orlowski RZ, Dai Y and Grant S. Targeting SQSTM1/ p62 induces cargo loading failure and converts autophagy to apoptosis via NBK/Bik. Mol Cell Biol. 2014; 34:34353449 .

63. Zhang HQ, Fang N, Liu XM, Xiong SP, Liao YQ, Jin WJ, Song RF and Wan YY. Antitumor activity of chloroquine in combination with Cisplatin in human gastric cancer xenografts. Asian Pac J Cancer Prev. 2015; 16:3907-3912.

64. Zhang HQ, He B, Fang N, Lu S, Liao YQ and Wan YY. Autophagy inhibition sensitizes cisplatin cytotoxicity in human gastric cancer cell line SGC7901. Asian Pac J Cancer Prev. 2013; 14:4685-4688.

65. Li LQ, Xie WJ, Pan D, Chen H and Zhang L. Inhibition of autophagy by bafilomycin A1 promotes chemosensitivity of gastric cancer cells. Tumour Biol. 2015.

66. Zhu BS, Sun JL, Gong W, Zhang XD, Wu YY and Xing CG. Effects of 5 fluorouracil and class III phosphoinositide 3kinase small interfering RNA combination therapy on SGC7901 human gastric cancer cells. Mol Med Rep. 2015; 11:1891-1898.

67. Choi PR, Kang YJ, Sung B, Kim JH, Moon HR, Chung HY, Kim SE, Park MI, Park SJ and Kim ND. MHY218induced apoptotic cell death is enhanced by the inhibition of autophagy in AGS human gastric cancer cells. Int J Oncol. 2015; 47:563-572.

68. Xu L, Qu XJ, Liu YP, Xu YY, Liu J, Hou KZ and Zhang Y. Protective autophagy antagonizes oxaliplatin-induced apoptosis in gastric cancer cells. Chin J Cancer. 2011; 30:490-496.

69. Zhan Z, Li Q, Wu P, Ye Y, Tseng HY, Zhang L and Zhang XD. Autophagy-mediated HMGB1 release antagonizes apoptosis of gastric cancer cells induced by vincristine via transcriptional regulation of Mcl-1. Autophagy. 2012; 8:109-121.

70. Marin JJ, Al-Abdulla R, Lozano E, Briz O, Bujanda L, Banales JM and Macias RI. Mechanisms of resistance to chemotherapy in gastric cancer. Anticancer Agents Med Chem. 2016; 16:318-34.

71. An Y, Zhang Z, Shang Y, Jiang X, Dong J, Yu P, Nie Y and Zhao Q. miR-23b-3p regulates the chemoresistance of gastric cancer cells by targeting ATG12 and HMGB2. Cell Death Dis. 2015; 6:e1766.

72. Ge J, Chen Z, Huang J, Chen J, Yuan W and Deng Z. Upregulation of autophagy-related gene-5 (ATG-5) is associated with chemoresistance in human gastric cancer. PLoS One. 2014; 9:e110293.

73. Kumar A, Singh UK and Chaudhary A. Targeting autophagy to overcome drug resistance in cancer therapy. Future Med Chem. 2015; 7:1535-1542.

74. Mukhopadhyay S, Panda PK, Sinha N, Das DN and Bhutia SK. Autophagy and apoptosis: where do they meet? Apoptosis. 2014; 19:555-566.

75. Du Y and Ji X. Bcl-2 down-regulation by small interfering
RNA induces Beclin1-dependent autophagy in human SGC7901 cells. Cell Biol Int. 2014; 38:1155-1162.

76. Jin $\mathrm{X}, \mathrm{Zhu} \mathrm{Z}$ and Shi Y. Metastasis mechanism and gene/ protein expression in gastric cancer with distant organs metastasis. Bull Cancer. 2014; 101:E1-12.

77. Su Z, Yang Z, Xu Y, Chen Y and Yu Q. Apoptosis, autophagy, necroptosis, and cancer metastasis. Mol Cancer. $2015 ; 14: 48$

78. Kessenbrock K, Wang CY and Werb Z. Matrix metalloproteinases in stem cell regulation and cancer. Matrix Biol. 2015; 44-46:184-190.

79. Hashimoto I, Koizumi K, Tatematsu M, Minami T, Cho S, Takeno N, Nakashima A, Sakurai H, Saito S, Tsukada $\mathrm{K}$ and Saiki I. Blocking on the CXCR4/mTOR signalling pathway induces the anti-metastatic properties and autophagic cell death in peritoneal disseminated gastric cancer cells. Eur J Cancer. 2008; 44:1022-1029.

80. Jung $\mathrm{CH}$, Ro SH, Cao J, Otto NM and Kim DH. mTOR regulation of autophagy. FEBS Lett. 2010; 584:1287-1295.

81. Ng TL, Leprivier G, Robertson MD, Chow C, Martin MJ, Laderoute KR, Davicioni E, Triche TJ and Sorensen PH. The AMPK stress response pathway mediates anoikis resistance through inhibition of mTOR and suppression of protein synthesis. Cell Death Differ. 2012; 19:501-510.

82. Hardie DG, Ross FA and Hawley SA. AMPK: a nutrient and energy sensor that maintains energy homeostasis. Nat Rev Mol Cell Biol. 2012; 13:251-262.

83. Avivar-Valderas A, Bobrovnikova-Marjon E, Alan Diehl J, Bardeesy N, Debnath J and Aguirre-Ghiso JA. Regulation of autophagy during ECM detachment is linked to a selective inhibition of mTORC1 by PERK. Oncogene. 2013; 32:4932-4940.

84. Avivar-Valderas A, Salas E, Bobrovnikova-Marjon E, Diehl JA, Nagi C, Debnath J and Aguirre-Ghiso JA. PERK integrates autophagy and oxidative stress responses to promote survival during extracellular matrix detachment. Mol Cell Biol. 2011; 31:3616-3629.

85. Lock R and Debnath J. Extracellular matrix regulation of autophagy. Curr Opin Cell Biol. 2008; 20:583-588.

86. Zhao Y, Guo Q, Chen J, Hu J, Wang S and Sun Y. Role of long non-coding RNA HULC in cell proliferation, apoptosis and tumor metastasis of gastric cancer: a clinical and in vitro investigation. Oncol Rep. 2014; 31:358-364.

87. Feng AN, Zhang LH, Fan XS, Huang Q, Ye Q, Wu HY and Yang J. Expression of SIRT1 in gastric cardiac cancer and its clinicopathologic significance. Int J Surg Pathol. 2011; 19:743-750.

88. Zhang L, Wang X and Chen P. MiR-204 down regulates SIRT1 and reverts SIRT1-induced epithelial-mesenchymal transition, anoikis resistance and invasion in gastric cancer cells. BMC Cancer. 2013; 13:290.

89. Huang R, Xu Y, Wan W, Shou X, Qian J, You Z, Liu B, Chang C, Zhou T, Lippincott-Schwartz J and Liu W. Deacetylation of nuclear LC3 drives autophagy initiation 
under starvation. Mol Cell. 2015; 57:456-466.

90. Qiu G, Li X, Che X, Wei C, He S, Lu J, Jia Z, Pang K and Fan L. SIRT1 is a regulator of autophagy: Implications in gastric cancer progression and treatment. FEBS Lett. 2015; 589:2034-2042

91. Qiao L, Liang N, Zhang J, Xie J, Liu F, Xu D, Yu X and Tian Y. Advanced research on vasculogenic mimicry in cancer. J Cell Mol Med. 2015; 19:315-326.

92. Ding YP, Yang XD, Wu Y and Xing CG. Autophagy promotes the survival and development of tumors by participating in the formation of vasculogenic mimicry. Oncol Rep. 2014; 31:2321-2327.

93. Jin Z, Jiang W and Wang L. Biomarkers for gastric cancer: Progression in early diagnosis and prognosis (Review). Oncol Lett. 2015; 9:1502-1508.

94. Cao Y and Klionsky DJ. Physiological functions of Atg6/ Beclin 1: a unique autophagy-related protein. Cell Res. 2007; 17:839-849.

95. Zhou WH, Tang F, Xu J, Wu X, Yang SB, Feng ZY, Ding YG, Wan XB, Guan Z, Li HG, Lin DJ, Shao CK and Liu Q. Low expression of Beclin 1, associated with high Bcl$\mathrm{xL}$, predicts a malignant phenotype and poor prognosis of gastric cancer. Autophagy. 2012; 8:389-400.

96. Chen YB, Hou JH, Feng XY, Chen S, Zhou ZW, Zhang XS and Cai MY. Decreased expression of Beclin 1 correlates with a metastatic phenotypic feature and adverse prognosis of gastric carcinomas. J Surg Oncol. 2012; 105:542-547.

97. Won KY, Kim GY, Lim SJ, Sung JY, Kim YW, Park YK, Lee $\mathrm{J}$ and Choi HS. Autophagy is related to the hedgehog signaling pathway in human gastric adenocarcinoma: prognostic significance of Beclin-1 and Gli2 expression in human gastric adenocarcinoma. Pathol Res Pract. 2015; 211:308-315.

98. Mathew R, Karantza-Wadsworth V and White E. Role of autophagy in cancer. Nat Rev Cancer. 2007; 7:961-967.

99. Yoshioka A, Miyata H, Doki Y, Yamasaki M, Sohma I, Gotoh K, Takiguchi S, Fujiwara Y, Uchiyama Y and Monden M. LC3, an autophagosome marker, is highly expressed in gastrointestinal cancers. Int J Oncol. 2008; $33: 461-468$
100. Liao W, Sun L, Wang C, Huang H, Liu J and Shi M. LC3Apositive "stone-like" structures predict an adverse prognosis of gastric cancer. Anat Rec (Hoboken). 2014; 297:653-662.

101. Puissant A, Fenouille N and Auberger P. When autophagy meets cancer through p62/SQSTM1. Am J Cancer Res. 2012; 2:397-413.

102. Mohamed A, Ayman A, Deniece J, Wang T, Kovach C, Siddiqui MT and Cohen C. P62/ubiquitin IHC expression correlated with clinicopathologic parameters and outcome in gastrointestinal carcinomas. Front Oncol. 2015; 5:70.

103. Levine B, Packer M and Codogno P. Development of autophagy inducers in clinical medicine. J Clin Invest. $2015 ; 125: 14-24$.

104. Wang T, Goodall ML, Gonzales P, Sepulveda M, Martin KR, Gately S and MacKeigan JP. Synthesis of improved lysomotropic autophagy inhibitors. J Med Chem. 2015; 58:3025-3035.

105. Vakifahmetoglu-Norberg $\mathrm{H}$, Xia $\mathrm{HG}$ and Yuan J. Pharmacologic agents targeting autophagy. J Clin Invest. $2015 ; 125: 5-13$.

106. Velikkakath AK, Nishimura T, Oita E, Ishihara $\mathrm{N}$ and Mizushima N. Mammalian Atg2 proteins are essential for autophagosome formation and important for regulation of size and distribution of lipid droplets. Mol Biol Cell. 2012; 23:896-909.

107. Klionsky DJ, Baehrecke EH, Brumell JH, Chu CT, Codogno P, Cuervo AM, Debnath J, Deretic V, Elazar Z, Eskelinen EL, Finkbeiner S, Fueyo-Margareto J, Gewirtz D, Jaattela M, Kroemer G, Levine B, et al. A comprehensive glossary of autophagy-related molecules and processes (2nd edition). Autophagy. 2011; 7:1273-1294.

108. Pattingre S and Levine B. Bcl-2 inhibition of autophagy: a new route to cancer? Cancer Res. 2006; 66:2885-2888. 